\title{
Pyrolysis of Sunflower Oil Mucilages for Fluxing Bitumen $^{+}$
}

\author{
Mihaela Bombos 1, Gabriel Vasilievici 1,*, Sanda Velea ${ }^{1}$, Adrian Radu 1, Elena-Emilia Oprescu 1, \\ Simona-Bianca Ghimis ${ }^{1}$ and Dorin Bombos ${ }^{2}$ \\ 1 National Research and Development Institute for Chemistry and Petrochemistry ICECHIM, 202 Spl \\ Independentei St., 060021 Bucharest, Romania; bombos.mm@gmail.com (M.B.); sanda.velea@icechim.ro \\ (S.V.); serenity12ar@gmail.com (A.R.); oprescuemilia@gmail.com (E.-E.O.); simonaghimis@gmail.com \\ (S.-B.G.) \\ 2 Petroleum-Gas University of Ploiesti, 39 Bucharest Blv., 100680 Ploiesti, Romania; \\ bombos.dorin@gmail.com \\ * Correspondence: gabi.vasilievici@gmail.com \\ + Presented at the 15th International Symposium "Priorities of Chemistry for a Sustainable Development" \\ PRIOCHEM, Bucharest, Romania, 30th October-1st November 2019.
}

Published: 15 October 2019

Keywords: fluxing bitumen; pyrolysis; mucilages

The reduction of greenhouse gas emissions requires increasing the use of energy from renewable sources and reducing dependence on fossil fuels and energy imports, thus contributing to the security of energy supply. Pyrolysis has proven to be a promising technique for converting biomass into fuel.

The mucilages used in the experimental program came from the refining of sunflower oil. Mucilages were characterized by thermal analysis, determination of density, viscosity, and saponification index. Stable dispersions of mucilages were obtained with a nonionic polyoxyethylene 20 sorbitan monooleate surfactant (Tween80). The molybdenum catalyst was prepared using ammonium heptamolibdate as precursor. The pyrolysis of mucilages was performed in a laboratory continuous stainless steel tubular reactor heated in an oven with temperature control system and automatic feeding pump. The pyrolysis experimental test was carried out at atmospheric pressure and $500{ }^{\circ} \mathrm{C}$ temperature in the isothermal reaction zone. The composition of the liquid fraction resulting from the pyrolysis was determined by gas chromatography (GC-MS/MS triple quadAgilent 7890 A). A road bitumen D 50/70 penetration grade was selected for the preparation of fluidized bitumen with pyrolysis products. The homogenization of the mixture of road flux and bitumen was carried out in a $250 \mathrm{~mL}$ autoclave provided with an anchor-type stirrer and a thermostatic heating jacket.

Results: The stability test of the prepared emulsions was carried out for crude mucilage and mucilage emulsions with different concentrations of emulsifier. The recorded stability curves showed that the stability of the mucilage emulsions improved with the increase of the emulsifier concentration up to $3 \% \mathrm{wt}$. The chromatogram of liquid phase compositions separated during the catalytic pyrolysis process in the presence of Mo catalyst showed a high content of unsaturated fatty acids and a low content of saturated fatty acids and linear aliphatic hydrocarbons

The stabilization of the mucilage from the refining of vegetable oil was achieved by re-emulsifying it in the presence of a nonionic surfactant. The main processes in pyrolysis of mucilages are decarboxylation which results in linear hydrocarbons and solvolysis of the lecithins and glycerides present in the by-product fatty acids. The pyrolysis liquid fractions contain compounds with optimum polarity for solubilizing the bitumen and for stabilizing its colloidal 
structure. The low volatility of these compounds does not adversely affect the aging characteristics of fluxed bitumen such as loss of mass and residual penetration.

Acknowledgments: The research was financially supported by MCI Core Programme in the frame of projects PN 19.23.01.02.

Conflicts of Interest: Authors declare no conflict of interest.

(c) 2019 by the authors. Licensee MDPI, Basel, Switzerland. This article is an open access article distributed under the terms and conditions of the Creative Commons Attribution (CC BY) license (http://creativecommons.org/licenses/by/4.0/). 